\title{
A NEW AND REMARKABLE DIATOM-EATING FLAGELLATE, JENNINGSIA DIATOMOPHAGA NOV. GEN., NOV. SPEC.
}

\author{
Asa. A. Schaeffer
}

Diagnosis. Shape, cylindrical, 180 microns long by 40 microns in diameter; very metabolic. Flagellum, large, 150 microns long. Cuticula with spiral striations 1 to 2 microns apart; numerous movable club shaped appendages about one and onehalf microns long on the striations. Large central nucleus, 35 microns in diameter. Large contractile vacuole near the anterior end. Several rod-like structures in the pharynx immediately internal to a large mouth at the anterior end. Numerous bodies in the form of rings or strongly biconcave discs from 1 to 3 microns in diameter, in the endoplasm; large clear spheres up to 6 microns in diameter sometimes present. Locomotion, creeping. Food, exclusively diatoms. Reproduction, asexually, by longitudinal fission. Habitat, marshes, among algae and diatoms.

This remarkable flagellate has come under my observation on three different occasions: February 27 and March 31, 1916, and March 5, 1918. In the three instances, material was collected from the Lonsdale marshes near Knoxville, and allowed to stand in vessels in the laboratory for several months. The organism may be considered rare, for frequent examinations of material from these marshes during the past five or six years has revealed its presence only three times.

This flagellate does not occur in large numbers, not more than a few hundred being found at any one time. And their length of life in the culture is as short as their number is small. In none of the three cases mentioned did they remain in the culture for more than a week. Its rarity, and the difficulty with which it may be cultured are unfortunate from the point of view of the biologist, for its predatory animal nature stands out in striking contrast to the plant-like character of some of its immediate relatives.

I propose for this organism the generic name Jenningsia, in honor of my friend Professor H. S. Jennings, and the specific name diatomophaga.

Jenningsia is one of the largest members of the flagellates. Although the average length is about 180 microns, several individuals were found which measured 260 microns, exclusive of the flagellum, which in these individuals measured 170 microns, and in the smaller individuals, 150 microns. The shape of the body is cylindrical, with slightly tapering anterior end and very blunt but also slightly tapering posterior end. The 
flagellum is very stout and during locomotion is directed straight ahead, only the apical part being usually in active motion (figs. 1, 2).

In the general character of its movements this organism resembles peranema. Locomotion is accomplished only by creeping, the organism being incapable of swimming. Violent metabolic movements accompany locomotion especially when an obstacle is encountered in its path. Only rarely is the organism stretched out straight. When the direction of locomotion is changed or when a strong stimulus is received from another organism the shape assumed during locomotion is entirely lost in a very violent twisting and kneading movement, which soon, however, gives way again to the cylindrical shape characteristic of locomotion. A very slight stimulus is sufficient to cause very marked metabolic movements.

The exact manner in which locomotion is brought about could not be ascertained satisfactorily, but it was observed that the tip of the flagellum was habitually bent in the form of a small loop which was used somewhat in the manner of a paddle so as to pull the organism along. During locomotion, it is worthy of note, the organism rolls over frequently though not regularly, differing in this respect from the peranemas.

Externally, Jenningsia is radially symmetrical like the euglenas. The body is covered with a thin cuticle which is marked with spiral striations that take their origin in the mouth. Small slender spindleshaped structures about one and one-half microns in length, which may readily swing about in the water, are attached to the striations at irregular intervals. These cuticular spindles are most numerous near the extreme anterior end.

Internally there are found: a large central oval nucleus about 35 microns in diameter with a central denser body about 15 microns in diameter; a complicated contractile vacuole system (similar to that found in euglenas) near the anterior end, which functions several times a minute; a complicated pharynx provided with stiff rod-like elements; and numerous strongly biconcave discs or rings of clear bluish green material, ranging from one to three microns in diameter. One or more large vacuoles are also occasionally found in the posterior half of the organism.

Of the structures just enumerated the pharynx is of especial interest although it is very difficult to understand its detailed operation while feeding. In the moving organism one can see two rod-like elements lying with their anterior ends in a clear space free from protoplasm and 
protected by a strong arched structure on the anterior side, the arch representing the lips of the closed mouth. When the animal is compressed under the cover glass the mouth is forced open and three large rods are now seen which are forced partly outwards (fig. 3). In this process some of the small rod-like elements disappear, which may indicate that these apparent rods are only folds of cuticle occasioned by the closure of the mouth and the retraction of the pharynx. Although I have seen the animal devour diatoms on several occasions I have been quite unable to determine exactly how the rods of the pharynx operate during this process.

Another element of interest are the numerous rings or discs scattered throughout the endoplasm (figs. 1, 4). They are of all sizes as stated above and are of a clear but pale bluish green color. They are unaffected by the ordinary stains or iodine but dissolve without visible change in solutions of $\mathrm{H}_{2} \mathrm{SO}_{4}$. In their general appearance, number, and behavior towards reagents they are similar to the crystals in amebas and may possibly be formed in a similar manner. They are not active under the polariscope. It is probable that these rings or discs are some by-product of metabolism.

In one culture of few but large individuals, numerous spherical bodies were observed which stained deeply with haematein. No food was observed in any of these individuals.

The most interesting thing about this organism from a general point of view is its mode of nutrition. It is completely holozoic. As indicated by its proposed specific name, its food is living diatoms of all sizes up to 100 microns in length. I have examined in all several hundred of these organisms and nearly all of them had from one to five diatoms, mostly of medium size, in them. No other food objects have been observed.

The feeding process is very difficult to observe in detail, owing to the violent metabolic movements, the activity of the complicated pharynx, and the speed with which the food is devoured. The organism moves along with the tip of the flagellum moving about until it comes into contact with a diatom. If hungry, the flagellum is brought into contact with the diatom as much as possible while the animal continues with its forward movement. When the anterior end of the organism comes nearly into contact with the diatom, the posterior end rears up and violent metabolic movements set in. The anterior end is brought over the 
diatom and is seen to spread out. The basal part of the flagellum is also seen to move about as if it had a part in the actual swallowing of the food particle. Presently the diatom is seen inside the flagellate, which moves away within a few seconds, the whole process of feeding taking place within about 20 seconds. Although I saw a number of instances of feeding and took particular pains to see whether the pharyngeal rods were actually protruded, or were used merely in distending the mouth, I was unable to determine their exact function. I incline to think however, that the rods were not protruded beyond the mouth opening. On several occasions I tested their reactions to carmine particles without obtaining positive responses, although one specimen so tested later devoured a diatom. All the evidence therefore indicates that Jenningsia is a predacious animal that feeds exclusively on living diatoms.

I observed but one instance of reproduction-asexual-which was accomplished by longitudinal splitting, beginning at the anterior end and extending backwards. One of the daughters inherits the old flagellum, the other grows a new one during division.

Jenningsia affords a very good example of the ease with which fundamental instincts and habits may be changed in phylogeny, for it is an animal descended from plants. The exclusively predacious instincts of this animal contrast strongly with the true holophytic mode of nutrition of some of the closely related family of euglenas. In so far as the actual process of feeding is concerned we have exhibited within the span of the single order Euglenineae all the general methods of nutrition known among nucleated organisms: true holophytic nutrition by means of chlorophyll among euglenas; saprophytic, the ingestion of decomposing nitrogenous foods either liquid (astasias) or solid (peranemas); holozoic, ingestion of carbohydrate or protein materials-pieces of animal or vegetal tissues (peranema); holozoic, ingestion of small masses of bacteria or pieces of animal and vegetal tissues and on living protophyta (dinema); holozoic, predacious, injestion only of living, moving organisms that, in a real sense, have to be captured (Jenningsia). No better illustration than this could be found of the combined plant and animal characters of the Flagellata.

The change from a holophytic to a holozoic type of nutrition in the Euglenineae has been made possible by the development of the pharynx. In the euglenas the pharynx is a simple tube-like depression at the anterior end whose chief function seems to be that of an efferent drainage 
canal for the contractile vacuole. But it also serves as a means of taking into the body small solid particles as has been shown by placing carmine in the culture fluid. The taking in of solid matter is however not an essential function for the euglena, but it is of interest in that it foreshadows saprophytic and holozoic instincts and modes of nutrition in the so-called colorless euglenas - the astasias-and in the peranemas.

The astasias have gone a step further than the euglenas. They have developed a larger pharynx and, we may suppose, one better adapted to taking in liquid food. At the same time they have also lost the chlorophyll from their bodies.

The peranemas have likewise gone a step further than the astasias in the development of the pharynx. In these organisms the pharynx is provided with special rods which make it possible to open and close the pharynx, and also to act somewhat like a suction apparatus by means of which solid matter may be eaten with despatch. Most of these organisms are small, so that they are restricted in their food to bacteria or small pieces of disintegrating organisms. In Jenningsia we have however as a most important development, a large size, so that it is possible for it to feed on such large actively moving organisms as diatoms in a truly predatory manner.

In company therefore with a progressively developing tendency in these organisms from holophytic to holozoic nutrition in a physiological sense, we have also, on the morphological side, a progressive development of the pharynx and of the size of the organism which makes possible the capturing and eating of relatively large masses of solid food and actively moving organisms.

University of Tenn., Knoxville, Tenn. 


\section{EXPLANATION OF PLATE}

Fig. 1. Jenningsia diatomophaga in locomotion. Body length, 180 microns, flagellum length, 150 microns, cv, contractile vacuole; $d$, ingested diatoms; e, excretion bodies; m; mouth; n, nucleus; p, pharynx; r, pharyngeal rods; v, vacuole.

Fig. 2. Photomicrograph of living $J$. diatomophaga in locomotion. The dark masses represent ingested diatoms. The basal part of the flagellum is seen at the anterior end.

Fig. 3. Sketch of anterior end compressed under cover glass to force open the mouth, m. s, cuticular striations originating in the mouth and running spirally around the organism; $r$, the pharyngeal rods.

Fig. 4. Enlarged view of "excretion" discs. a, top view; b, cross section. 


\section{$2 \mathrm{BHL}$ Biodiversity Heritage Library}

1918. "A New and Remarkable Diatom-Eating Flagellate, Jenningsia diatomophaga nov. gen., nov. spec." Transactions 37, 177-182.

View This Item Online: https://www.biodiversitylibrary.org/item/86816

Permalink: https://www.biodiversitylibrary.org/partpdf/90913

\section{Holding Institution}

University of Toronto - Gerstein Science Information Centre

\section{Sponsored by}

University of Toronto

\section{Copyright \& Reuse}

Copyright Status: Not provided. Contact Holding Institution to verify copyright status.

This document was created from content at the Biodiversity Heritage Library, the world's largest open access digital library for biodiversity literature and archives. Visit BHL at https://www.biodiversitylibrary.org. 